\title{
¿MÁS PARTICIPACIÓN IGUAL A MEJOR DEMOCRACIA? ACERCA DE LA CRÍTICA A LA DEMOCRACIA PARTICIPATIVA
}

ALFREDO RAMÍREZ NÁRDIZ 
SUMARIO

I. INTRODUCCIÓN. II. CRISIS DE LA REPRESENTACIÓN Y DEMOCRACIA PARTICIPATIVA. III. CRÍTICAS A LA DEMOCRACIA PARTICIPATIVA. 1. La acusación de populismo. 2. La simplificación de la política. 3. La imposibilidad material y el rol de internet. 4. La necesidad del control. 5. La atracción de lo representativo. IV. CONCLUSIONES. V. BIBLIOGRAFÍA. VI. JURISPRUDENCIA. VII. PÁGINAS WEB. 


\title{
¿MÁS PARTICIPACIÓN IGUAL A MEJOR DEMOCRACIA? ACERCA DE LA CRÍTICA A LA DEMOCRACIA PARTICIPATIVA
}

\author{
ALFREDO RAMÍREZ NÁRDIZ \\ Universidad Libre, Seccional Barranquilla ${ }^{1}$
}

\section{INTRODUCCIÓN ${ }^{2}$}

La relación entre representación y participación dentro del sistema democrático adquiere particular relevancia en el presente cuando uno de los elementos nucleares de la mayoría de las críticas a la actual democracia representativa consiste en acusarla de permitir una escasa participación real de los ciudadanos en la toma de decisiones políticas para, acto seguido, exigir de ella una mayor participación mediante la introducción de instrumentos de democracia participativa en la toma de las decisiones políticas y, en general, en el conjunto de la vida pública. La consideración de que merced a los instrumentos participativos la democracia puede fortalecerse al acercar el poder a los ciudadanos no es en absoluto nueva y se ha desarrollado en contextos políticos y sociales tan diferen-

${ }^{1}$ Profesor Contratado Doctor (Acreditado ANECA). Universidad Libre, Seccional Barranquilla. Km. 7. Antigua vía a Puerto Colombia. A. A. 1752, Barranquilla, Colombia. aramirez@ unilibrebaq.edu.co alfredoramireznardiz@hotmail.com.

${ }^{2}$ Este artículo es producto del proyecto de investigación «Transformaciones democráticas y democracia participativa» perteneciente al grupo de investigación «Poder público y ciudadanía» de la Universidad Libre, Seccional Barranquilla, km. 7. Antigua vía a Puerto Colombia. A. A. 1752, Barranquilla, Colombia. aramirez@unilibrebaq.edu.co. 
tes como, por ejemplo, el periodo de entreguerras ${ }^{3}$, donde una democracia parlamentaria frágil se encontraba sitiada por fascismos y comunismo y donde la participación se veía como herramienta para implicar a los ciudadanos ${ }^{4}$ en la democracia y evitar su fagocitación por los totalitarismos ${ }^{5}$, o como los años sesenta y setenta del siglo Xx cuando, si algún problema tenía para sus críticos la democracia representativa, era precisamente el contrario al que padeció décadas antes y consistía en que se había conseguido su consolidación, pero esta se había hecho alrededor de parámetros elitistas ${ }^{6}$ que habían llevado a que los ciudadanos apenas fueran tenidos en cuenta más que para ratificar en elecciones periódicas a sus gobernantes ${ }^{7}$, siendo por ello y desde esta lógica necesarios los

3 «Durante mucho tiempo, y hasta el período de entreguerras, las instituciones de democracia abierta y semidirecta no se aceptaron. Será con la Constitución de Weimar de 1919 y con las que ésta inspira cuando se incorporarán a diversos ordenamientos fundamentales intentando armonizarlas con el elemento representativo». LuCAs Verdú, P. (1981): «Constitución española de 1978 y sociedad democrática avanzada», Revista de Derecho Político, n. ${ }^{\circ} 10$, p. 35.

4 «Desde finales de la I Guerra Mundial se han buscado vías para conseguir una mayor participación de los ciudadanos en la adopción de decisiones, en la vía de introducir institutos de democracia semi-directa, que complementen la democracia representativa y acerquen a los ciudadanos a las decisiones». Molas, I. (2011): Derecho constitucional, Madrid, Tecnos, p. 99.

5 Así Kelsen ya en 1920 indicaba en Esencia y valor de la democracia y respecto de la iniciativa popular que «aun cuando no sea posible, por razones de técnica social, dejar que el pueblo forme directamente y en todos sus grados el orden estatal, es factible concederle en las funciones legislativas mayor participación de la que se le otorga en el sistema parlamentario, en el que queda reducida al acto electoral» y en Teoría general del Derecho y del Estado que «en el proceso legislativo es preciso combinar, en cierta medida, el principio de la democracia indirecta con el de la directa». En la dirección apuntada, Otto señalaba respecto a la postura de Kelsen sobre la participación directa de los ciudadanos en la toma de decisiones políticas que «sus propuestas se dirigen a una mayor vinculación del Parlamento con el elector, lo que no es posible sin una activación de éste y, por tanto, sin una prolongación de su actividad política más allá de la acción de depositar su voto en una urna». Kelsen, H. (1977): Esencia y valor de la democracia, Madrid, Guadarrama, Colección Punto Omega, introducción y p. 64; Kelsen, H. (1979): Teoría general del Derecho y del Estado, Méjico D. F., Dirección general de publicaciones de la Universidad Nacional Autónoma de Méjico, p. 355.

${ }^{6}$ En palabras de Schumpeter, la democracia «no significa ni puede significar que el pueblo gobierna efectivamente, en ninguno de los sentidos evidentes de las expresiones pueblo y gobernar», pues la democracia significa «que el pueblo tiene la oportunidad de aceptar o rechazar los hombres que han de gobernarle (...) la libre competencia entre los pretendientes al caudillaje por el voto del electorado». SCHumpeter, J. A. (I97 I): Capitalismo, socialismo y democracia, Madrid, Aguilar, p. 362.

7 «La mayor parte de los sistemas democráticos actualmente vigentes en el mundo, y particularmente en Europa, practican un modelo de democracia profundamente restrictivo. Se trata de un modelo que, siguiendo a Schumpeter, reduce la democracia a la condición de un simple método regulador de la conducta de la lucha de la competencia (Schumpeter 1968, 315 ss.)». JAUREGUI 
instrumentos participativos como medio para acercar el poder a los ciudadanos ante la deriva de la democracia ${ }^{8}$ y al objeto de regenerarla, pues ya no se encontraba en peligro de desaparición como la democracia del periodo de entreguerras, sino supuestamente degenerada y necesitada de más participación para regenerarse.

Frente a esta postura optimista respecto a la relación entre democracia representativa y democracia participativa, tampoco es nueva la postura opuesta ${ }^{9}$, que considera que la introducción de instrumentos participativos en la democracia representativa es, en el mejor de los casos, una mezcla de géneros de la que no es bueno abusar ${ }^{10}$, y, habitualmente, un peligroso camino para que populistas, demagogos y enemigos de la democracia ya alcancen, ya aumenten, ya simplemente mantengan el poder apelando a un constituyente activo de manera permanente, eviten las instituciones representativas y creen relaciones más propias de un sistema caudillista entre líder carismático y ciudadanía vista como todo, como pueblo dentro del cual deja de haber divisiones internas pues todas quedan superadas por la voluntad única manifestada en el instrumento participativo, que de uno verdaderamente democrático ${ }^{11}$.

Bereciartu, G. (1998): «Democracia: ¿declive temporal u ocaso definitivo?», Revista internacional de filosofía política, n. ${ }^{\circ} 11$, p. 104.

8 Habermas citando a Scharpf cuestionaría el modo y la eficacia en que una democracia de élites puede realmente servir a los ciudadanos e identificar sus necesidades, pues «los grupos de líderes, que compiten unos con otros, no quedan obligados, en lo que a sus objetivos se refiere, por la confianza inespecífica y altamente agregada de las masas pasivas de electores, sólo la racionalidad de las propias élites dispuestas a la innovación y capaces de tomar decisiones puede garantizar aún un cumplimiento de las funciones estatales orientado al bien común». Habermas, J. (1998): Facticidad y validez. Sobre el derecho y el Estado democrático de derecho en términos de teoría del discurso, Madrid, Trotta, pp. 410-411.

9 Esta ha sido históricamente (al menos hasta fechas recientes) el punto de vista típicamente inglés tal y como manifestó el primer ministro británico Attlee: «no podría aceptar la incorporación en nuestra vida política de una institución ajena a nuestras tradiciones y que frecuentemente ha servido de instrumento al nazismo y al fascismo». Atrtlee, C. (I954): As it happened, Londres, Heinemann, p. 137.

${ }^{10}$ Apuntaba en el periodo constituyente Alzaga respecto a la forma y modo de regular los instrumentos participativos: «Estamos, por supuesto, también en la línea de incorporar a esa democracia básicamente representativa importantes ingredientes participativos o de democracia semi-directa. Pero alguien dijo, con fino sentido, que la combinación de géneros plantea una gravedad distinta en política que en literatura». Herrero Lera, M. citando el BOC n. ${ }^{\circ} 109$, de 13 de julio de 1978, pp. 4208-4209, en Alzaga Villaamil, Ó. (1985): Comentarios a las Leyes Políticas. Constitución Española de 1978, tomo VII, Madrid, Revista de Derecho Privado, Editoriales de Derecho Reunidas, pp. 216-217.

${ }^{11}$ Bien conocida es la crítica de Sartori: «la democracia refrendaria centuplica los riesgos de manipulación y embrollos del demos, más allá de cuánto haya logrado el demagogo del que tene- 
Este diálogo acerca de si una mayor participación directa de los ciudadanos en la toma de las decisiones políticas es o no útil para una mejor democracia se encuentra hoy en día de especial actualidad al ser la petición de más participación una de las más recurrentes en las actuales críticas a la democracia representativa. ${ }^{12}$ Ciertamente, la tradicional reflexión sobre la crisis de la representación, que destaca la intensa diferencia entre el concepto ideal de representación parlamentaria y la realidad de las democracias, deriva en el presente en una crítica prácticamente generalizada al modelo político representativo ${ }^{13}$, personalizado en los partidos políticos a los que se suele acusar de todos o, como mínimo, de la mayoría de los problemas de la democracia. Frente a esta situación, una mayor participación directa de los ciudadanos en la toma de las decisiones políticas aparece poderosa como opción. Tanto doctrinal, como política ${ }^{14}$, como popularmente, las apelaciones a la necesidad de más participación son frecuentes. Saber

mos conocimiento (...) Con la democracia refrendaria se toca el momento de la verdad en el que el ideal de la democracia etimológica sería realizado al pie de la letra y se tocaría también, preveo, el momento en el cual el ideal se vuelve su opuesto y se autodestruye (el éxito inverso en el que cae, sin falta, el perfeccionista) (...) la democracia representativa es a menudo mal gobierno pero de todas formas es democracia. Temo que donde llegaba a haber una presunta superación, la democracia dejaría rápidamente de ser tal». SARTORI, G. (2007): op. cit., pp. 125-131.

${ }^{12}$ Indica en este sentido Rubio Núñez que «la sociedad reclama una mayor relación con sus gobernantes y la doctrina se ha fijado, en los últimos años, en el concepto de participación política. Se buscan formas alternativas, o complementarias, a la representación». RUBIO NúÑEZ, R. (2007): «La guerra de las democracias», Asamblea: revista parlamentaria de la Asamblea de Madrid, n. ${ }^{\circ} 16$, pp. 81-88.

13 «(...) la incapacidad de los actuales sistemas democráticos para adecuarse a las nuevas realidades y situaciones. El desfase entre la sociedad civil y las instituciones, entre la constitución material y la constitución formal, resulta lisa y llanamente abismal». JAUREGUi BERECIARTU, G. (1998): op. cit., p. 103.

14 A modo de ejemplo, quepa citar la web del partido político Podemos. Que la participación sea un elemento destacado en las webs de los partidos políticos españoles es habitual en el presente y, así por ejemplo, tanto en la web del PP, como del PSOE, como (especialmente y por la originalidad y variedad de herramientas audiovisuales puestas a disposición del internauta) en la de Ciudadanos, se dedican amplios espacios a la misma, si bien es tal vez en la de Podemos donde es posible encontrar afirmaciones más decididas. Así, en el apartado dedicado al programa (para las elecciones al Parlamento Europeo de 2014) se dice: «Podemos es un método para el protagonismo popular y ciudadano. Queremos que nuestro programa se conforme a través de la participación de la ciudadanía y los Círculos Podemos. Nadie sabe mejor qué es lo que necesitamos que los ciudadanos que día a día sacan adelante el país». El apartado de la web dedicado a participación aparece destacado y en él se puede leer: «Uno de los elementos diferenciales de la nueva política es el protagonismo ciudadano, ampliando su inclusión en la construcción de iniciativas y proyectos que entre todos y todas queremos sacar adelante. Estamos demostrando que la democracia no es votar una vez cada 4 años, sino que el ejercicio de la ciudadanía se practica día a día (...)» PODEMOS, podemos.info, consultado el 22/01/2015. 
si este aumento de la participación es realmente viable y, en el caso de serlo, si mejora o no la democracia es una de las cuestiones constitucionales posiblemente más interesantes de la actualidad.

En estas líneas se busca exponer sucintamente la relación entre la actual formulación de la crisis de la representación y la democracia participativa como hipotético elemento corrector, para a continuación analizar algunas de las más habituales críticas a la democracia participativa y tratar de proponer una posible respuesta a la cuestión de si una mayor participación directa conlleva o no una mejor democracia.

Con carácter previo al desarrollo del presente artículo es importante realizar una precisión acerca del término democracia participativa y del uso que se le da en este texto. Frente a la conceptualización establecida por el Tribunal Constitucional en su STC 103/2008, de 11 de septiembre, FJ. 2. ${ }^{\circ}$, donde se distingue entre instrumentos de democracia directa (referendos, iniciativa legislativa popular y concejo abierto), que son los recogidos en el texto constitucional en desarrollo del derecho de participación política del art. 23.1 CE, y fenómeno participativo, que se compone de múltiples formas de participación en la vida pública derivadas del mandato general para promover la participación que hace la Constitución en los arts. 9.2 CE y 48 CE (y donde cabría incluir las consultas populares, los presupuestos participativos, los jurados ciudadanos, etc. Pero también derechos subjetivos ajenos al de participación política como, por ejemplo, el de participación en la enseñanza del 27.5 CE), este texto parte de una terminología diferente que distingue entre instrumentos de democracia participativa e instrumentos de participación ciudadana, siendo el elemento diferenciador que el ciudadano decida o no en dichos instrumentos (sea esta decisión vinculante o no, sea una decisión que inicie el proceso o lo termine). Esta opción terminológica particular surge del deseo de distinguir los instrumentos participativos que se considera que verdaderamente suponen un aumento de la participación del ciudadano en la toma de decisiones públicas (democracia participativa), frente a aquellos (participación ciudadana) que no implican toma de decisiones y que, por ejemplo, pueden limitar la participación a un intercambio de información entre la administración y el ciudadano. Igualmente, el abandono del término democracia directa se debe a considerarlo propio de una realidad diferente a la consistente en introducir instrumentos participativos en un modelo esencialmente representativo, que es de lo que se trata en el presente ${ }^{15}$. En

15 Para un mayor detalle sobre la opción terminológica asumida en estas líneas se remite al «Glosario» de la obra RAmírez NÁRDIZ, A (2012): Guía práctica de la democracia participativa. Conocer la democracia participativa y aprender a usarla, Madrid, Dykinson. 
este sentido, este artículo tiene por objeto de análisis la democracia participativa vista como todo, en abstracto, entendida como un concepto dentro del cual cabrían tanto los, en terminología del TC, instrumentos de democracia directa (referendos, ILP y concejo abierto) como los de democracia semi-directa o mera participación (consultas, presupuestos, jurados, etc.) siendo su elemento definidor y común que el ciudadano no se limite a participar/relacionarse con el poder público, sino que decida. La democracia participativa no es, en ningún caso, un bloque monolítico y, por ello, si bien las distintas críticas que en este artículo se plantean se predican de ella como todo, son en especial aquellos instrumentos que consisten en una pregunta directa (generalmente sólo con dos respuestas posibles antagónicas entre sí), aquellos en terminología de Sartori de democracia refrendaria ${ }^{16}$, los que más claramente pueden ser objeto de las críticas aquí expuestas.

\section{CRISIS DE LA REPRESENTACIÓN Y DEMOCRACIA PARTICIPATIVA}

La crisis de la representación es un referente clásico del constitucionalismo ${ }^{17}$. Como bien ha sido dicho ${ }^{18}$, no es descabellado afirmar que existe crisis de la representación prácticamente desde que existe representación. Según el momento histórico, las críticas sobre la discordancia entre el ideal de la representación que surge con las revoluciones liberales y la realidad de la vida democrática diaria de cualquier país que haya adoptado esta forma de gobierno han ido cambiando y adaptándose a las coyunturas concretas de cada generación, pero crisis de la representación, en cierto modo, siempre ha habido y, tal vez, mientras exista la democracia representativa, siempre habrá ${ }^{19}$. Hoy esta

16 Sartori, G. (2007): ¿Qué es la democracia?, México, D. F., Taurus, pp. 125-131.

17 En palabras de Asensi Sabater: «la crisis de la representación política y de los parlamentos, un tema abordado ad nauseam desde diferentes enfoques y con diferentes intenciones». AsENSI Sabater, J. (2012): "Crisis teórica, transiciones constitucionales», Revista Derecho del Estado, n. ${ }^{\circ} 28$, p. 21.

18 Fernández-Miranda Campoamor, C. y Fernández-Miranda Campoamor, A. (2003): Sistema electoral, partidos políticos y parlamento, Madrid, Colex, pp. 37-38.

19 Como señala de Vega, es inevitable que siempre exista una cierta discordancia entre la norma y la realidad regulada al ser ésta un sujeto en movimiento y al tener aquella que seguirla siempre en una continua evolución: «sólo desde la inconsecuencia más absoluta se podría esperar y predicar la coincidencia entre norma y realidad. Si la realidad no es una «orden fija» y «fechada», establecida de una vez para siempre, la coincidencia plena entre los proyectos normativos y los ámbitos normativos (F. Müller; Hesse, Escritos de derecho constitucional, pág. XVII) tiene por fuerza que resultar imposible». VEGA, P. de (1998): «Mundialización y Derecho Constitucional: 
crítica adquiere en no poco modo la forma de una enmienda al modelo en su conjunto o, cuando menos, a gran parte del mismo ${ }^{20}$, indicándose que los vicios que padece no son meramente formales o cosméticos, no afectan sólo a alguno o algunos de sus elementos constitutivos, sino que el mal se extiende al núcleo mismo de la democracia representativa al haberse roto la necesaria relación de confianza entre representantes y representados, pues se señala que no representan ya aquellos a estos, sino que sólo sirven como herramienta al servicio del poder que las oligarquías económicas ejercen sobre el pueblo cada vez más depauperado ${ }^{21}$. Particulares críticas reciben en esta dirección los partidos políticos y su papel de «intermediarios necesarios» ${ }^{22}$, especie de pseudoinstituciones del Estado $^{23}$, que monopolizan la vida pública y que generan una dinámica que acaba haciendo girar las instituciones democráticas, las organizaciones sociales e incluso a la democracia misma alrededor de ellos impidiendo, o cuando menos dificultando enormemente, cualquier tipo de vida política fuera de ellos ${ }^{24}$. La crítica llega a descalificar a los representantes y

la crisis del principio democrático en el constitucionalismo actual», Revista de estudios políticos, n. ${ }^{\circ} 100$, p. 30 .

20 «La «crisis de representación» del Parlamento no es un fenómeno reciente sino que refleja, como es bien sabido, una larga historia de conflictos sociales, que, en las diferentes coyunturas, viene a medir el grado de representatividad que el sistema político está dispuesto a admitir. Lo problemático, hoy, es la naturaleza y el alcance de la crisis». Asensi Sabater, J. (2002): «La reanimación del parlamento: exigencia de un «constitucionalismo consecuente»», Corts: Anuario de Derecho parlamentario, n. ${ }^{\circ} 12$, p. 42.

${ }^{21}$ Especialmente significativa, resumen en gran medida de un tiempo, es la pregunta que la web de Podemos lanza al lector en su apartado dedicado a las elecciones europeas de 2014: «¿Cuándo fue la última vez que votaste con ilusión?» La afirmación que viene a continuación no deja lugar a la duda: «Vivimos en un momento de enorme dificultad y empobrecimiento para la inmensa mayoría de las personas, mientras que un hatajo de corruptos se está enriqueciendo a costa de robarnos la democracia». PODEMOS, podemos.info, consultado el 03/02/2015.

${ }^{22}$ La crítica a los partidos políticos no es en absoluto algo reciente. Como apunta Lucas Verdú, ya desde el liberalismo clásico «surgirán críticas, advertencias y sospechas sobre los partidos a los cuales se les califican, peyorativamente, como facciones. Se teme que al organizarse fuertemente dificulten la fluidez representativa y que intercepten la formación y expresión de la voluntad nacional». LuCAS Verdú, P. (1981): op. cit., p. 34.

23 «Desde entonces, los partidos de todo signo, siguiendo la lógica cratológica, se han ido acercando al estado, hasta tal punto que resulta difícil no confundirlos como parte de sus aparatos». Asensi Sabater, J. (2002): op. cit., p. 45.

24 «Quizás uno de los problemas políticos más serios del presente consista en la tendencia de los partidos a introducirse en el seno de las organizaciones sociales para influenciarlas y dirigirlas. Es el fenómeno de la tan denostada «politización» (mejor sería decir «partidización») de las empresas económicas, sociales y culturales (...)» ARAGón REYES, M. (2000): «Democracia y 
gobernantes en su conjunto referenciándolos como clase ${ }^{25}$ o casta ${ }^{26}$, pues se les acusa no sólo de no representar a la sociedad, sino de ni siquiera formar parte de ella constituyéndose como grupo social con intereses, dinámicas y objetivos propios y ajenos a los ciudadanos ${ }^{27}$. Se construyen discursos en los que se polariza la sociedad entre ciudadanos maltratados y gobernantes maltratadores. Buenos y malos. Gente decente y élites explotadoras ${ }^{28}$. Se ve cada vez más la democracia representativa como mera estructura de justificación del poder económico sobre los ciudadanos ${ }^{29}$, hasta el punto de dejar a las constituciones vacías de la función de canalizar el conflicto social y político negando la existencia del mismo e imponiendo como condición de partida a todo debate político una serie de apriorismos económicos que cualquier operador político ha de asumir como algo inevitable con independencia de cuál sea la propuesta ideológica con la que se presente a los ciudadanos ${ }^{30}$.

representación. Dimensiones objetiva y subjetiva del derecho de sufragio», Corts: Anuario de Derecho parlamentario, n. ${ }^{\circ}$ 9, p. 44.

${ }^{25}$ La utilización de la palabra clase para referirse a la élite política gobernante no es hija del presente. Como indica Dahl, Mosca utiliza la expresión clase dirigente como sinónimo de clase política y Pareto se sirve de las fórmulas clase gobernante o clase dominante, siendo que Dahl opta por el término minoría dominante. DAHL, R. A. (1992): La democracia y sus críticos, Barcelona, Paidos, p. 323.

26 En este sentido: Montero, D. (2009): La casta: el increíble chollo de ser político en España, Madrid, La esfera de los libros.

${ }^{27}$ La concepción de la clase política como una élite ajena al ciudadano y a sus intereses es habitual. La misma democracia representativa se caracteriza recurrentemente como elitista: «Nuestro sistema representativo, en efecto, demuestra tener raíces profundamente elitistas: la idea que a él subyace, parece ser, es la de que unos pocos individuos elegidos pueden entender, explicar, o evaluar adecuadamente, las preferencias y los intereses de todos los demás afectados». GARGARELLA, R. (1994): «Crisis de representación, deliberación y "political correctness»», Anuario de filosofía del Derecho, n. ${ }^{\circ} 11$, p. 247.

${ }^{28}$ Esta dialéctica está presente en los movimientos populares surgidos en los últimos años en países como España. Estos movimientos se ven a sí mismos como opositores a gobiernos corruptos que no representan al pueblo. En función de ello, tanto protestan contra dicho gobierno, como proponen cambios legales y constitucionales. En este sentido analizan el $15 \mathrm{M}$ autores como Presno Linera. Presno Linera, M. A. (2014): «Partidos políticos y movimientos ciudadanos en la sociedad del riesgo y la desconfianza», La metamorfosis del Estado y del Derecho, Fundamentos: Cuadernos monográficos de teoría del estado, derecho público e historia constitucional, n. ${ }^{\circ} 8$, Universidad de Oviedo, pp. 213-252.

29 «La crisis ha resuelto la paradoja: ha quedado claro que el Derecho, en las actuales circunstancias, es sirviente de la Economía, o mejor dicho, de un modelo económico sin contornos precisos, que impone no obstante su ley». Asensi Sabater, J. (2012): op. cit., p. 33.

30 «Se aplican políticas preestablecidas en virtud de determinados criterios económicos, sea cual sea el resultado de esos procesos y sin atender a los programas que los propios partidos gobernantes presentaron a las elecciones». BALAguer Callejón, F. (2013): «Una interpreta- 
En esta línea, si una mala representación es el problema, una buena participación es la solución ${ }^{31}$. Este podría ser el lema de la democracia participativa, vista como complemento ${ }^{32}$ de una democracia representativa que habría de regenerarse ${ }^{33}$, acercarse a los ciudadanos, volver a representar sus intereses y recuperar la legitimidad perdida ${ }^{34}$. La democracia participativa, entendida como el conjunto de instrumentos participativos que pretende lograr una mayor implicación de los ciudadanos en la toma de decisiones políticas y en la vida pública, aumentar el control sobre sus representantes y alcanzar una mejor democracia como objetivo final ${ }^{35}$, aparece para sus defensores como un elemento crucial para la solución de los actuales problemas de la democracia. ¿Cuáles serían las utilidades de la democracia participativa para mejorar la democracia representativa? Por citar algunas posibles ${ }^{36}$ : mejora del intercambio de información entre las administraciones públicas y los ciudadanos; aumento de la

ción constitucional de la crisis económica», Revista de Derecho Constitucional Europeo, n. ${ }^{\circ}$ 19, pp. 451-452.

${ }^{31}$ Recuerda Lissidini citando a Offe — citado a su vez por Gargarella — que «muchos críticos de las prácticas de la democracia liberal, particularmente desde la izquierda política, han tendido a creer que la obvia cura a los resultados injustos e irrazonables de las acciones de gobierno, es la de ampliar los márgenes de la participación democrática y la co-determinación» Lissidini, A. (1998): «Una mirada crítica a la democracia directa: El origen y las prácticas de los plebiscitos en Uruguay», Perfiles latinoamericanos: Revista de la Facultad Latinoamericana de Ciencias Sociales, Sede México, n. ${ }^{\circ}$ 12, p. 170.

32 Complemento y no substitutivo, pues parece idea generalmente aceptada que el rol de la participación es complementar la representación, no substituirla. En este sentido, Aragón Reyes apunta que «(...) las dificultades prácticas y los graves inconvenientes teóricos de la democracia directa han originado que ésta no pueda verse como una alternativa a la democracia representativa sino, todo lo más, como su complemento». Ibídem, p. 42.

33 A modo de crítica a las apelaciones a la regeneración de la democracia apunta de Vega que «no han faltado los agoreros y críticos de la democracia constitucional que, apelando a un tipo ideal de Constitución, reconstruyen imaginariamente un modelo que sitúan en un pretérito inventado, para desde él denunciar los males y las perversiones del presente». VEGA, P. de (1998): op. cit., p. 30.

34 «(...) uno de los grandes retos actuales de la democracia consiste en recuperar su capacidad para satisfacer esos intereses de los ciudadanos, y no aquellos intereses identificados, moldeados y seleccionados colectivamente a través de intermediarios, con el argumento de que representan los intereses de los ciudadanos». Jauregui Bereciartu, G. (1998): op. cit., p. 123.

35 Se sigue aquí, a modo de propuesta, la definición dada en Ramírez NÁrdiz, A (2012): Guía práctica de la democracia participativa. Conocer la democracia participativa y aprender a usarla, Madrid, Dykinson.

36 Se sigue en la enumeración de utilidades a RAmírez NÁrdiz, A. (2014): «La participación como respuesta a la crisis de la representación: el rol de la democracia participativa», Revista de Derecho Político, UNED, n. ${ }^{\circ}$ 90, pp. 197-199. 
participación de los ciudadanos ${ }^{37}$; aumento de la formación de los ciudadanos ${ }^{38}$; identificación más intensa del ciudadano con la comunidad de la que forma parte; revalorización de la democracia como modelo político; mayor respaldo popular de las decisiones tomadas por los poderes públicos; mejora de la imagen de los políticos, los partidos políticos y la política en general.

Aun y estas potenciales utilidades, que parecerían confirmar el carácter complementario y pacífico de la relación entre representación y democracia participativa $^{39}$, la realidad de la tensión entre ambas y particularmente entre participación directa y partidos políticos no ha de resultar muy sorprendente tan pronto como se percibe que el ejercicio de la primera debilita el rol de intermediario entre el ciudadano y la toma de decisiones políticas que ejercen los segun$\operatorname{dos}^{40}$. En cierto modo, la democracia participativa aparece como un competidor en el mercado político en el que los partidos acostumbrar a ser el máximo, si no el único, actor de referencia ${ }^{41}$. La compleja relación entre unos y otra, que lleva a intentar minimizar a la una por $\operatorname{los}_{\text {otros }}{ }^{42}$ y a criticar a los otros por los defen-

37 Como indica Held, cuando los ciudadanos saben que pueden participar en la toma de decisiones posiblemente acabarán pensando que la participación merece la pena, participando activamente y defendiendo que las decisiones colectivas sean obligatorias. Sin embargo, si se les margina, o no se les representa adecuadamente y no se les tiene en cuenta acabarán pensando que participar no merece la pena. Held, D. (1992): Modelos de democracia, Madrid, Alianza, p. 312.

38 Esta utilidad de la democracia participativa es especialmente destacada en instrumentos participativos como los presupuestos participativos donde los participantes no sólo deben conocer la legislación mínima aplicable, sino también aspectos prácticos de las cuestiones que se vayan a decidir popularmente (construir una plaza, un colegio, asfaltar una calle...). Por citar dos ejemplos, quepa destacar las experiencias de Porto Alegre (Brasil) o de Kerala (India), donde miles de personas recibieron formación específica sobre las materias sobre las que posteriormente votaron. RAMírez NÁRDiz, A. (2014): op. cit., pp. 200-203.

39 En esta dirección de entender la democracia participativa como un complemento, como un conjunto de modelos participativos y procesos decisionales que se introducen en la democracia representativa, pero no como un modelo que pueda substituir o equipararse con la democracia representativa se posicionan autores como Floridia. FloridiA, A. (2007): «La democrazia deliberativa, dalla teoria alle procedure. Il caso della legge regionale toscana sulla partecipazione», Istituzioni del federalismo: rivista di studi giuridici e politici, n. ${ }^{\circ}$ 5, p. 636.

40 «Actualmente presenciamos la existencia de un cada vez más extendido discurso «democrático» que hace permanente alusión a la importancia de la participación ciudadana en los asuntos públicos, asentado sobre instituciones políticas que restringen al máximo dicha participación y dificultan aún la comunicación entre la clase dirigente y sus electores». GARGARELLA, R. (1995): «Crisis de representación y constituciones contramayoritarias», Isonomía: Revista de teoría y filosofía del Derecho, n. ${ }^{\circ}$ 2, p. 91.

41 Lucas Verdú, P. (1981): op. cit. p. 37.

42 En este sentido, resulta esclarecedor el proceso constituyente español y el modo en que se reguló en el texto constitucional la democracia participativa, siendo que en las distintas argumen- 
sores de la una, parece un hecho más allá de la apariencia de colaboración entre el modelo representativo y el participativo que podría extraerse de ver recogidos en los textos constitucionales algunos instrumentos participativos que, sin embargo y a poco que se analice la casuística, tienen, salvo excepciones notables, poco recorrido práctico real ${ }^{43}$.

La democracia participativa debe encuadrarse dentro del marco general de las corrientes participacionistas que buscan replantear las relaciones entre sociedad y gobierno ${ }^{44}$ recuperando el espacio público, activando al ciudadano como sujeto político movilizado y partiendo de la deliberación como elementos regeneradores de un modelo democrático representativo al que se considera eminentemente elitista y del que se afirma que lleva al aislamiento político del ciudadano y a su sometimiento a los designios del mercado y la economía ${ }^{45}$. Se parte del diagnóstico de los males o, cuando menos, de las carencias del modelo representativo liberal para ofrecer una mayor participación e implicación del ciudadano en la vida pública como elemento corrector ${ }^{46}$.

taciones dadas en sede parlamentaria se reconoció abiertamente la necesidad de darle preeminencia al modelo representativo y especialmente al sistema de partidos antes que regular demasiados instrumentos participativos. Vide: Ramírez NÁrdiz, A. (2009): «El debate en torno a los mecanismos de democracia participativa durante el proceso constituyente español», Cuadernos constitucionales de la Cátedra Fadrique Furió Ceriol, n. ${ }^{\circ}$ 67-68, pp. 167-178.

43 Baste citar la experiencia española donde desde 1978 en que se regularon constitucionalmente el referendo y la iniciativa legislativa popular y la primera mitad de los ochenta en que se desarrollaron legislativamente, la práctica a nivel nacional ha sido prácticamente nula (dos referendos consultivos, ninguno constitucional...), la autonómica no ha sido mucho mayor (cuatro de diecisiete CCAA han ratificado sus Estatutos mediante referendo), residiendo apenas en el ámbito local la innovación y la práctica participativas mínimamente referenciables. Vide RAMíREZ NÁRDIZ, A (2012): op. cit.

${ }_{44}$ Define Luigi Bobbio, siguiendo a Allegretti, la democracia participativa como una nueva relación de la sociedad con las instituciones, que implica una intervención de las expresiones directas de la primera en los procesos de acción de la segunda. BoвBIo, L. (2006): «Democrazia partecipativa- Dilemmi della democrazia partecipativa», Democrazia e diritto, n. ${ }^{\circ} 4$, p. 11.

45 Siendo que, en palabras de Häberle, la economía para poder ser considerada como análoga a la democracia debe ser social: «sólo la economía social de mercado puede ser objeto limitado de una analogía con la democracia pluralista, de manera que el ciudadano mercantil sea el ciudadano democrático». HäBERLE, P. (2006): «Siete tesis para una teoría constitucional del mercado», Revista de Derecho Constitucional Europeo, n. ${ }^{\circ} 5$, p. 23.

46 En palabras de Habermas: «El eje del modelo liberal no es la autodeterminación democrática de ciudadanos deliberantes, sino la normación (en términos de Estado de Derecho) de una sociedad centrada en la economía que a través de la satisfacción de las expectativas de felicidad (siempre de carácter privado) de ciudadanos activos habría de garantizar un bien común entendido en términos apolíticos». Habermas, J. (2005): «Tres modelos de democracia: sobre el concepto de una política deliberativa», Polis: Revista Latinoamericana, n. ${ }^{\circ} 10$. 
Frente a este modelo representativo liberal, y desde una perspectiva que busca fortalecer la sociedad civil construida alrededor de la deliberación, la participación y la solidaridad, se plantea una concepción de la vida pública en la que el ciudadano participe y se convierta en verdadero actor político que contribuya a crear un modelo social menos dependiente de las imposiciones del mercado y más democrático ${ }^{47}$ en tanto en cuanto procedente de la voluntad agregada de todos los ciudadanos ${ }^{48}$.

La democracia participativa genera, no obstante, diversidad de críticas que, haciendo un muy grosero resumen, llevarían a indicar que una mayor participación directa del ciudadano en la vida política, especialmente, si se vehicula a través del recurrente instrumento participativo que es la pregunta directa con dos respuestas alternativas y antagónicas, no tiene por qué llevar a una mejor democracia ${ }^{49}$, sino que, justo al contrario, puede provocar un empobrecimiento democrático al ser susceptible de debilitar las instituciones representativas, sometiendo elementos nucleares de la democracia, tales como el Estado de Derecho, la separación de poderes o la misma garantía de los derechos individuales, tanto a la voluntad popular manifestada en la imposición del criterio de la mayoría sobre las minorías, como a una potencial dinámica caudillista entre aquel que

47 «La fuerza de integración social que tiene la solidaridad, que ya no cabe extraer sólo de las fuentes de la acción comunicativa, habrían de poder desarrollarse a lo largo y ancho de espacios públicos autónomos ampliamente diversificados y de procedimientos de formación democrática de la opinión y la voluntad política, institucionalizados en términos de Estado de Derecho, y habría de poder afirmarse también frente y contra los otros dos poderes, es decir, frente al dinero y el poder administrativo». Ibídem.

48 Pues, en caso contrario, el riesgo que se sufre es el que, en relación con los peligros de la tecnocracia, señala Jáuregui Bereciartu: «El concepto de ciudadanía se debilita progresivamente. La tecnocracia no percibe a los individuos como ciudadanos, como sujetos públicos de derechos y obligaciones, sino como piezas de una serie de procesos continuos de producción y consumo. Lo que importa de los individuos no es tanto su calidad de ciudadanos sino, sobre todo, su condición de asalariados, consumidores, o contribuyentes. De este modo la democracia corre el riesgo de disolverse en una libertad reducida a la del consumidor en el mercado». Jauregui Bereciartu, G. (2014): «Democracia y sociedad tecnológica», Revista vasca de administración pública, n. ${ }^{\circ} 99-100$, p. 1744.

49 Un razonamiento similar aparece, por ejemplo, tras la consideración de que un sistema electoral más proporcional no tiene por qué ser mejor para la democracia, aun e incorporando mayor justicia electoral al modelo, pues puede derivar en una mayor fragmentación parlamentaria y, por ende, en una mayor dificultad para alcanzar una mínima estabilidad que permita una buena gobernabilidad. En esta dirección apunta Dahl (DAHL, R. A. (2009): La poliarquía. Participación y oposición, Madrid, Tecnos, pp. 197-201). Es decir, mayor oferta electoral, mayor opción de voto, mayor democracia (entendida como más opciones de participación), no sería, por tanto y desde este punto de vista, garantía de mejor democracia. 
organiza el instrumento participativo y la ciudadanía llamada a pronunciarse en el mismo ${ }^{50}$.

\section{CRÍTICAS A LA DEMOCRACIA PARTICIPATIVA}

Sin ánimo de realizar una enumeración exhaustiva ${ }^{51}$, sino tan sólo de describir brevemente algunas posibles críticas que se pueden formular frente a la democracia participativa quepa destacar dos categorías de críticas: aquellas que centran el foco en los operadores de los instrumentos participativos (es decir, que detectan mala fe en quién promueve el instrumento participativo) y aquellas que lo hacen en las propias características de la democracia participativa y sus carencias inherentes. En las primeras se podría incluir la acusación de que la democracia participativa genera populismo (si no es en sí populismo), o la consideración de que simplifica peligrosamente la política. En las segundas se encontrarían la indicación de que materialmente es imposible gobernar una sociedad mediante instrumentos participativos (y la respuesta que se da en contra apelando a las TIC), la falta del necesario control que debe existir sobre cualquier manifestación de poder y sobre sus actores, y que es complejo que se dé en el ejercicio de un instrumento participativo, o la afirmación de que, inserta en un modelo esencialmente representativo, acaba por ser fagocitada por la dinámica representativa no cumpliéndose sus objetivos participativos. En conjunto, estas críticas inciden en una idea general: la democracia participativa no mejora necesariamente la democracia ${ }^{52} \mathrm{y}$, si su regulación y aplicación no es acertada, puede incluso empeorarla.

50 Diferencia Presno Linera entre las críticas procedentes de las tesis elitistas (citando los ejemplos de Burke, Schumpeter o Sartori), que combatirían toda participación de los ciudadanos que vaya más allá de votar en elecciones representativas periódicas, y las procedentes de lo que Hirschman llama las tesis del riesgo, que considerarían que permitir la participación directa podría poner en peligro algunos de los logros de la democracia. Presno Linera, M. A. (2012): «La participación ciudadana en el procedimiento legislativo como parte de la esencia y valor de la democracia», Asamblea: revista parlamentaria de la Asamblea de Madrid, n. ${ }^{\circ} 27$, p. 88.

${ }^{51} \mathrm{La}$ enumeración nunca puede ser cerrada, ni mucho menos excluyente. Subirats cita «la falta de continuidad y de estrategia definida en la opinión de la ciudadanía, la falta de información y debate suficiente, sin asunción de responsabilidades sobre los efectos de las decisiones tomadas, el peligro de falta de participación que permita el control del voto en ciertas decisiones por parte de minorías con intereses muy definidos, o el exceso de complejidad en las políticas o decisiones a tomar, o los problemas derivados del propio uso de las TIC, su control, garantías». SubiRAts I Humet, J. (2011): «¿Qué democracia tenemos? ¿Qué democracia queremos?», Historia actual online, n. ${ }^{\circ} 26$, p. 130 .

52 En este sentido y en relación con los procesos constituyentes indican Bejarano y Seguro que: «Buena parte de la literatura sobre constitucionalismo parte de la siguiente premisa: cuanto 
La democracia participativa, tal como se la entiende en el presente artículo, no puede ser vista, en ningún caso, como un todo uniforme y las críticas aquí expuestas deben ser entendidas, si bien a la misma como todo, especialmente a aquellos instrumentos participativos que, dentro de ella y cercanos a lo que Sartori definiera como democracia refrendaria, consisten en una pregunta directa a los ciudadanos que generalmente no prevé más que dos respuestas opuestas e incompatibles entre sí.

\section{La acusación de populismo}

La principal crítica que se plantea a la democracia participativa es que, en no pocos casos, la voluntad de sus promotores no es la mejora democrática mediante la introducción de instrumentos participativos en la democracia representativa, sino, por el contrario, la consecución de sus intereses particulares ${ }^{53}$. Esta inversión del objetivo ideal de la democracia participativa, de uno general a otro particular, si se materializa en la búsqueda de los intereses del gobernante sobre los de los gobernados a través del instrumento participativo, podrá provocar el debilitamiento del modelo representativo y de las instituciones que lo componen, particularmente del parlamento, así como el fortalecimiento del Ejecutivo mediante el establecimiento de una relación directa entre su titular y el pueblo, al que se apelará repetidamente a través de los instrumentos participativos para ratificar las propuestas gubernamentales y fortalecer al Gobierno frente a la oposición parlamentaria ${ }^{54}$.

más democrático, abierto, incluyente y participativo sea el proceso, más democrática habrá de ser la constitución (ver Hart 2003; Chambers 2004; Elster 1997, entre otros). Nuestros hallazgos empíricos evidencian que este tipo de procesos conducen, por lo general, a textos constitucionales más incluyentes y participativos, con listas de derechos expandidas, así como innovaciones en el campo de la participación no-electoral. Sin embargo, los mismos ponen en duda la tendencia a asumir que todo proceso constituyente participativo conduce, necesariamente, a la profundización de la democracia; entendiendo que ésta implica no sólo mayor inclusión y participación, sino también la existencia de instituciones que garanticen igualdad de condiciones para todas las fuerzas en pugna, incluidas, por supuesto, aquellas que se sitúan en el campo de la oposición». BEJARano, A. M. y Segura, R. (2013): «Asambleas constituyentes y democracia: una lectura crítica del nuevo constitucionalismo en la región andina», Colombia Internacional, n. ${ }^{\circ}$ 79, p. 43.

53 «(...) en muchas oportunidades la intencionalidad de los que proponen y/o ponen en práctica los mecanismos de democracia directa responde a intereses políticos específicos y no a intenciones «democratizadoras»». Lissidini, A. (1998): op. cit., p. 171.

${ }^{54}$ Este fenómeno será especialmente relevante en países en los que la organización del poder tienda a la concentración y al protagonismo del Ejecutivo, pues la utilización de la democracia participativa podrá llevar a la potenciación de este protagonismo gubernamental. Particularmen- 
Así, la democracia participativa implicar apelar al ciudadano llamándole a votar sobre diversas cuestiones. Pero, ¿quién elige esas cuestiones? Pues todos los ciudadanos votan, pero no todos eligen sobre lo que se vota ${ }^{55}$. En última instancia alguien debe decidir sobre lo que se propone a los ciudadanos votar ${ }^{56}$. Y las posibilidades de que ese alguien, que más que probablemente será el titular del Ejecutivo, aparezca como el líder natural, como el interlocutor necesario con el pueblo, son elevadas. El guía que les señalará a los ciudadanos en qué dirección ir, pues, además de seleccionar los temas sobre los que se votará, también les indicara cuál es la opción que él defiende y apoya en cada votación, la cual nunca será la que más le conviene a él, sino la que más conviene al pueblo, que siempre tiene razón, con quien él se identifica y es uno ${ }^{57}$.

El peligro de personalizar la vida pública y que finalmente las votaciones no sean otra cosa que estar a favor o en contra del líder de turno es elevado. No es descabellado pensar que, en estas circunstancias, un líder ratificado repetidas veces en sus propuestas por los ciudadanos mediante instrumentos participativos

te, en países como los latinoamericanos, en los cuales es habitual que la figura del Presidente de la República centralice el ejercicio del poder, la utilización de instrumentos participativos corre el riesgo de convertirse en medio para aumentar aún más la preponderancia del Presidente frente a cualquier otra institución. En este sentido, apunta Gargarella que si bien las constituciones latinoamericanas contemporáneas han recogido amplias tablas de derechos y han buscado el progreso social y democrático de sus países, han mantenido la tradicional estructura decimonónica de concentración del poder en la figura del Presidente, ahogando y desvirtuando con ello los derechos recogidos en los textos constitucionales, entre ellos los relativos a la participación. GARGARELLA, R. (2013): «Dramas, conflictos y promesas del nuevo constitucionalismo latinoamericano», Anacronismo e irrupción. Revista de Teoría y Filosofía Política Clásica y Moderna, vol. 3 , n. ${ }^{\circ} 4$, p. 255.

55 «Quiénes serían los que elaboran los refrendos? Aunque quedaran algunos individuos elegidos a título representativo, en la democracia refrendaría el juego y la puesta en juego cambian radicalmente. Primero, toda la partida está en decidir la agenda (qué es lo que sí hay que someter a decisión y qué no) y, segundo, el modo de formular tales interrogantes» SARTORI, G. (2007): op. cit., p. 124.

56 «En general el sentido de la información es unidireccional, e incluso cuando existe la posibilidad de la bidireccionalidad, el control del medio y la decisión sobre la oportunidad o no de tener en cuenta las opiniones ajenas, recaen sobre el aparato del partido o la dirección de la institución. En este caso no se trata de dar más opciones a los ciudadanos-consumidores, sino de generar consenso hacia la organización, o de facilitar la labor de advocacy o de lobbying desde el exterior, pero siempre entendiendo que existen unos «expertos» en la institución que decidirán que conviene tener en cuenta, que conviene asumir y que no». Subirats i Humet, J. (2011): op. cit., p. 123.

57 «Por este camino el que vence es el demagogo, el manipulador por excelencia de la soberanía popular. El demagogo que se apoya en las muchedumbres gritando que el pueblo tiene siempre la razón». SARTORI, G. (2007): op. cit., p. 129. 
acabe considerando (si no fue esa, precisamente, su voluntad desde un comienzo) que la ratificación es personalmente sobre él y que, por tanto, ninguna institución del Estado (ya legislativa, ya judicial) está legitimada para limitar su poder o, simplemente, controlarle. El resultado acaba siendo el debilitamiento de las instituciones del Estado y el establecimiento de una relación caudillista entre el líder y el pueblo, visto como todo uniforme (sin fisuras, ni diferencias de opinión en él) al que apelar para ratificar las propuestas del Gobierno. Con este debilitamiento institucional los límites y controles al gobernante también se debilitan y, finalmente, la democracia pierde calidad.

El ejemplo posiblemente más característico de este favorecimiento del personalismo que fomentan algunos instrumentos participativos sea la revocatoria de mandato, la cual puede hacer que la vida política de una localidad, región o Estado gire alrededor de una persona, no de una ideología o un programa político. Ya sea desde el punto de vista hasta cierto punto desenfadado (por el candidato favorito) que se le dio en 2003 en California, donde se revocó el mandato de Gray Davis eligiendo gobernador a Arnold Schwarzenegger ${ }^{58}$, o el de intenso conflicto social con el que se vivió en 2004 la fallida revocatoria de Hugo Chávez en Venezuela ${ }^{59}$, ambos procesos, como todos aquellos de revocatoria, versaron en gran medida sobre la persona, haciendo que una sociedad se parta en dos en función de que apoye o no a esa persona ${ }^{60}$.

Tal vez, un medio para comprobar si la voluntad última del gobernante que fomenta y apela a la democracia participativa es la profundización democrática o, por el contrario, la consolidación del propio poder, sea comprobar cómo están estructuradas y cuál es el equilibrio entre las instituciones del Estado, si han sido

58 El actor, no en vano apodado «Gobernator» y que tiene entre sus películas una llamada «Total Recall» (lo que podría traducirse como «Revocatoria total»), llegó a parafrasear a uno de sus personajes y dijo en sus discursos «Hasta la vista, Gray Davis». QvorTRUP, M. «La experiencia estadounidense de 1776 a 2012», en WELP, Y. y SERDüLT, U. (2014): La dosis hace el veneno. Análisis de la revocatoria de mandato en América Latina, Estados Unidos y Suiza, Quito, Instituto de la Democracia, pp. 207-208.

59 Sobre Venezuela afirma Rubio Núñez: «Chávez no ha dejado de afirmar su régimen a costa de la democracia, transformada en «participativa», «popular»y, finalmente, «de partido único», preludio de la tiranía. Tras las elecciones del 4 de diciembre de 2005 se ha acelerado este proceso autocrático, y hoy Hugo Chávez ejerce casi todos los poderes del Estado, ha comenzado a extender su «revolución» por Hispanoamérica y amenaza con perpetuarse en el poder a través de un referéndum». RuBio NúÑEZ, R. (2006): «Venezuela. La pesadilla revolucionaria y el camino hacia el totalitarismo», La Ilustración liberal: revista española y americana, n. ${ }^{\circ}$ 29, pp. 89-100.

60 Esto, por supuesto, es una reflexión sobre la práctica, pues en la teoría países como Colombia en sus Leyes 131 y 134 de 1994 indican que la revocatoria de mandato puede ponerse en marcha en el caso de que previamente se haya producido una violación del voto programático, es decir, del programa electoral del candidato ahora revocado. 
modificadas bajo la promoción de dicho gobernante (mediante una reforma constitucional o mediante una nueva Constitución) y hasta qué punto la introducción de instrumentos participativos forma o no parte de una estrategia general de fortalecimiento del papel del Ejecutivo en la elaboración de las decisiones políticas ${ }^{61}$.

\section{La simplificación de la política}

Dentro de esta crítica aparecen diferentes aspectos que tienen en común el indicar que una mayor participación lleva a una peligrosa involución de la necesaria complejidad de la democracia, la reducción de su nivel técnico y un empeoramiento general en el modelo ${ }^{62}$.

Así, una de las críticas más recurrentes a la democracia participativa indica que la misma hace caer la democracia en simplistas disyuntivas maniqueas al forzar por un lado al ciudadano a elegir entre dos opciones por un lado enfrentadas (o se elige una, o se elige la otra, sí o no ${ }^{63}$ y, por otro lado, irreconciliables (no es posible la negociación y el acuerdo en un punto intermedio y mutuamente satisfactorio, sino que debe optarse plenamente por una opción y desechar por completo la otra). En cierta manera y visto desde este punto de vista, la democracia participativa haría de la política algo primitivo (uno gana, otro pierde $)^{64}$, fomentaría peligrosamente el enfrentamiento y el conflicto entre los

${ }^{61}$ Así, respecto a dos de las Constituciones que mayor número de instrumentos participativos regulan en el presente, Venezuela 1999 y Ecuador 2008, indican Bejarano y Segura que «allí los procesos constituyentes aumentaron los poderes presidenciales, crearon Congresos unicamerales con menor capacidad para ejercer el control político sobre el Ejecutivo, mantuvieron poderes judiciales dependientes del poder presidencial y revirtieron la tendencia anterior a la descentralización, transformaciones todas que afectan en forma negativa el equilibrio de poderes, a favor del Ejecutivo y en detrimento de las demás ramas del poder». Bejarano, A. M. y SEgura, R. (2013): op. cit., p. 42.

${ }^{62}$ La reflexión acerca de la superioridad técnica de la democracia representativa y de los efectos perniciosos que puede tener la participación directa es tan antigua como la aparición de la democracia representativa. Como apunta Gargarella haciendo referencia a Madison y sus palabras en el número 10 de El Federalista: «el sistema representativo no es un mero «segundo mejor» ante la imposibilidad de la democracia directa, sino un bien necesario y superior, frente a la incapacidad que demuestra la ciudadanía en la práctica de la democracia directa». GARGARELLA, R. (1995): op. cit., p. 95.

63 Así, los dos referendos consultivos celebrados en España: OTAN sí, OTAN no; Constitución Europea sí, Constitución Europea no.

${ }^{64}$ Sobre este carácter esencialmente primitivo de la participación directa, frente al esencialmente moderno de la representación, apunta Lucás Verdú que «las instituciones de democracia directa y semidirecta proceden de un mundo tradicional, comunitario y aldeano. En cambio, los partidos políticos son formaciones modernas, societarias que se convierten en maquinarias (...) las 
ciudadanos (al dividirlos en dos grupos enfrentados ${ }^{65}$ por apoyar o rechazar una determinada propuesta sometida a voto refrendario) ${ }^{66}$, ignoraría la voluntad de las minorías ${ }^{67}$ imponiendo la de las mayorías ${ }^{68}$ e impediría crear acuerdos sociales transversales fomentando en su lugar una concepción agresiva y no pactista de la democracia, siendo que dicha concepción deliberativa ${ }^{69}$, pactista, integra-

instituciones de democracia directa arrancan de un mundo basado en la espontaneidad de la comunidad vital configurada por un derecho predominantemente consuetudinario; en cambio, la democracia representativa supone un notable grado de reflexión de discusión y de contraste entre opiniones variadas que sólo prosperan en las aulas parlamentarias». LuCAS Verdú, P. (1981): op. cit., p. 36.

65 Tal vez, en ocasiones habría que hacer la lectura a la inversa. Esto es, no es que la democracia participativa fomente que la sociedad se organice en dos grupos enfrentados, sino que la existencia de dos grupos enfrentados se visualiza gracias a la democracia participativa, la cual, incluso, puede ser el medio por el que uno de esos dos grupos adquiere un protagonismo político del que tradicionalmente se ha sentido privado. Así, por ejemplo, no resulta imposible ver el desarrollo de la democracia participativa en las constituciones latinoamericanas más recientes como parte de un intento general de dichos textos por dotar de presencia pública a grupos (indígenas, pobres, fuerzas de izquierda, etc.) históricamente apartados de las grandes decisiones políticas de los países del subcontinente. En este sentido: «Buena parte del entusiasmo alrededor de los recientes episodios de cambio constitucional en las naciones andinas está relacionado con su potencial para crear mayores espacios de inclusión y participación en la vida pública, revirtiendo así la tendencia histórica a la exclusión de amplios sectores sociales». Bejarano, A. M. y SEgura, R. (2013): op. cit., p. 37.

66 «También importa comprender bien cuáles son las implicaciones de una democracia con suma nula. La primera es que la suma nula tiende a agravar los conflictos: si quien pierde, pierde todo, entonces la derrota hostiga; y si ello se repite día tras día, puede resultar intolerable. De este modo, tenemos un método de «solución» de conflictos que a la postre los agrava». SARTORI, G. (2007): op. cit., p. 125.

${ }^{67}$ Cuando no hay que olvidar que uno de los elementos nucleares de la democracia representativa es precisamente el respeto a las minorías: «La democracia representativa no consiste sólo en que sea representativo el gobierno sino también en que lo sea la oposición, esto es, en que no sólo se eligen gobiernos sino también parlamentos, comprensivos de las mayorías y de las minorías. Justamente porque el parlamento, a través del sufragio, representa a todos (...) es por lo que cabe hablar de democracia pluralista (...)» Aragón Reyes, M. (2000): op. cit., p. 55.

68 «(...) la democracia refrendaria instaura, de hecho, un principio mayoritario absoluto que viola el principio (fundamentalísimo) del respeto a la minoría. Los refrendos no dan la cara a nadie y sólo atropellan los derechos de las minorías (...) la tan temida «tiranía de la mayoría» —en la acepción fuerte del término- es una eventualidad poco verosímil en las democracias representativas, pero encontraría una aplicación segura en la democracia refrendaria». SARTORI, G. (2007): op. cit., p. 125.

69 Como indica Vallespín en relación al rol de las redes sociales: «No es lo mismo, en efecto, ayudar a movilizar a determinados sectores del público que facilitar el aspecto deliberativo de la democracia». VAllespín OÑA, F. (2011): «Redes sociales y democracia: ¿un cambio cualitativo?», Telos: Cuadernos de comunicación e innovación, n. ${ }^{\circ}$ 89, pp. 57-60. 
dora y plural es precisamente uno de los más destacados y característicos elementos de la democracia representativa, de la democracia moderna en su conjunto $^{70}$.

Junto con este elemento, se tiende a acusar también a la democracia participativa de sacar la toma de decisiones políticas del parlamento, donde sujetos dedicados profesionalmente a la cosa pública debaten, negocian y dedican un importante tiempo a elaborar y aprobar las normas jurídicas, a la calle, donde ciudadanos dedicados a la política de forma amateur aprobarán o rechazarán las cuestiones que les sean planteadas sin la suficiente reflexión, debate y tiempo necesarios para conseguir los mejores resultados. Desde esta perspectiva, la democracia participativa, al arrebatar el poder de las manos de los profesionales y dejarlo en las de aficionados, podría llevar, en definitiva, a una banalización de la democracia y a una bajada en la calidad tanto de la ley, como del gobierno de la comunidad ${ }^{71}$. Por supuesto, la consideración última de la que se parte aquí es asumir que el ciudadano medio es políticamente incapaz o, cuando menos, no suficientemente formado para asumir verdaderas decisiones políticas más allá de la elección de sus representantes ${ }^{72}$.

Igualmente, es posible indicar que algunos de los instrumentos de la democracia participativa tienden a mostrar una visión falsamente homogénea de la sociedad (si no, incluso, a homogeneizarla al obligar a los ciudadanos a optar

${ }_{70}$ «La opción por la democracia representativa no tiene sólo a su favor razones de puro pragmatismo, sino también muy sólidos fundamentos teóricos, basados en que la sociedad no es uniforme, sino plural, en que el gobierno de una comunidad ha de hacer posible la composición de intereses diversos, en que no puede sobrevivir el Estado sin una actividad permanente de integración (...)» ARAGón ReYes, M. (2000): op. cit., p. 42.

${ }^{71}$ Resuenan aquí poderosos los argumentos de Schumpeter y su diferenciación entre las esferas de responsabilidad directa e indirecta de todo ciudadano, siendo que la participación política se encuadra dentro de la esfera de responsabilidad indirecta y, por ello, el ciudadano le dedica menos tiempo e interés. SCHUMPeter, J. A. (1971): Capitalismo, socialismo y democracia, Madrid, Aguilar.

72 «El punto en el que se alude a la falta de preparación de la ciudadanía para enfrentarse a la complejidad de los temas que hoy nutren los debates legislativos es probablemente el más de fondo. Voces como las de Schumpeter o Sartori han afirmado que la ciudadanía no tiene el interés suficiente para seguir debates de fondo e interesarse por temas que no estén muy conectados a sus intereses más inmediatos. Por otro lado argumentan que la tecnificación de muchos de los debates sobre alternativas ante problemas concretos aleja a la ciudadanía de su posible implicación. Su implicación en la decisión, afirman, sólo podría afectar negativamente la calidad del resultado final (...) En el fondo uno acaba pensando que los argumentos contra la democracia directa basados en la falta de formación suficiente de los ciudadanos para tomar decisiones, podrían servir igual para argumentar contra la misma democracia genéricamente definida». Subirats i Humet, J. (2011): op. cit., p. 130. 
entre sólo dos opciones opuestas entre sí). Particularmente, aquellos que como el referendo se resuelven eligiendo entre un «sí» y un «no» transmiten la imagen de que la sociedad no es, como de hecho son las sociedades y más las contemporáneas, heterogénea y compleja, con una pluralidad de ideologías, sensibilidades e intereses, sino un todo sencillo, homogéneo y en el que la pluralidad se limita a la división en dos bandos (necesariamente opuestos e irreconciliables, como lo son las opciones de un referendo) alrededor de los cuales se aglutinan los ciuda$\operatorname{danos}^{73}$.

\section{La imposibilidad material y el rol de internet}

¿Cómo es posible organizar instrumentos participativos en sociedades como las actuales con cientos de miles o millones de kilómetros cuadrados de superficie y decenas o cientos de millones de habitantes no esporádicamente, como es práctica habitual, sino de modo constante y continuado? ¿Cómo se puede hacer que todo un país viva en «estado permanente de participación», como si de un poder constituyente activo ininterrumpidamente se tratara? Ante la inmensidad del objetivo, la respuesta bien podría ser que simplemente no se puede. Existe una imposibilidad material ${ }^{74}$. Frente a esta negación, el discurso sobre la democracia participativa acostumbra a apelar a las TIC, las tecnologías de la información y la comunicación ${ }^{75}$.

73 Esta tendencia a simplificar la complejidad social no es exclusiva de la democracia participativa. En relación con el concepto de sociedad civil apunta Vallespín que detrás de él «no se esconde sino un intento por representar como unidad a un sujeto social fraccionado y diverso (...) Esta necesidad de unificación de lo disperso y fraccionado, como se manifiesta también en la sólida presencia contemporánea de los comunitarismos, tiene sin embargo la virtud de aproximarnos a algunas de las «patologías» de nuestro sistema social y político, como son la ausencia de un sujeto democrático unitario y el problema central de la integración normativa, así como a los límites y posibilidades de conectar a la ciudadanía con el sistema político». VALLESPín OÑA, F. (1996): «Sociedad civil y «crisis de la política»», Isegoría: Revista de filosofía moral y política, n. ${ }^{\circ} 13$, p. 57.

74 «El límite teórico de la participación política efectiva disminuye rápidamente con la escala, aunque se recurra a los modernos medios de comunicación electrónicos». DAHL, R. A. (1992): op. cit., p. 262.

75 «La información y la comunicación son la esencia de todo proceso participativo (Manual OCDE) y las TICs son el instrumento idóneo para ello». Hasta el punto de que algunas nuevas normas jurídicas que regulan instrumentos participativos incorporan las NTIC como herramienta necesaria para su desarrollo: «el Reglamento (UE) n. ${ }^{\circ} 211 / 2011$, sobre la iniciativa ciudadana europea (ICE), una norma revolucionaria por cuanto está pensada esencialmente para internet». Cotino Hueso, L. (2012): «La regulación de la participación y de la transparencia a través de 
Democracia participativa e internet aparecen habitualmente como dos elementos de un mismo todo ${ }^{76}$. Se suele indicar que la democracia participativa - $\mathrm{O}$ incluso la democracia directa (entendida no como un complemento de la representativa, sino de su substitutivo) - ${ }^{77}$, que de otra manera sería imposible en los Estados del presente, se hace posible gracias a la inmediatez y las posibilidades que ofrecen las TIC y, particularmente, internet. Gracias a las TIC aparece como factible lo que apenas unas pocas décadas atrás resultaba ciencia-ficción: organizar frecuentes (si no constantes) consultas populares para someter al voto popular todas o gran parte de las cuestiones políticas y textos legislativos de un país. Organizarlas incluso remotamente mediante los dispositivos electrónicos a los que cada ciudadano pueda acceder en su domicilio, lugar de trabajo, espacio público o, de hecho, en cualquier parte si se tienen en cuenta los dispositivos móviles. Organizarlas sin necesidad de largas campañas de propaganda, pues del mismo modo que se puede votar por internet, se puede recibir y seleccionar la información por internet ${ }^{78}$. Organizarlas a bajo coste e incluso ecológicamente, pues no es necesario utilizar papel en ningún momento del proceso y no es necesario trasladarse al colegio electoral quemando combustibles fósiles en el trayecto. Hacer, en definitiva, un ágora contemporánea en la que del mismo modo que

internet y medios electrónicos. Propuestas concretas», P3T Journal of public policies and territories, n. ${ }^{\circ}$ 2, vol. 1, pp. 29-30.

76 Esto no significa que siempre se cumpla lo que se dice: «Pese a que toda institución se apunte a la moda de ponerse un 2.0 detrás o un «open» delante, lo cierto es que poco o nada - bueno- hay regulado al respecto de la participación y transparencia y, en especial, al uso de las TICs al respecto (...) un exceso regulador constriñe la participación, pero esto no se arregla con normas participativas vaporosas y jurídicamente insustanciales (...) la única causa de que las regulaciones sean mayormente simbólicas y propagandísticas es la falta de una verdadera voluntad política para asumir compromisos concretos y exigibles de transparencia, apertura y participación (...)» Ibídem, pp. 29-31.

77 «Tras la variada terminología, cabe advertir, suele esconderse una cierta — si se me permite- «teledemagogia», un intento de aprovechar los nuevos instrumentos tecnológicos para superar la actual democracia hacia fórmulas de democracia directa». Cotino Hueso, L. (2007): «Retos jurídicos y carencias normativas de la democracia y la participación electrónicas», Revista catalana de Dret públic, n. ${ }^{\circ} 35$, p. 78.

${ }^{78}$ Otra cuestión es qué información se recibe o, especialmente, cuál decide seleccionar el ciudadano. Como indica Vallespín, citando a Pariser (The filter bubble, 2011), existe una tendencia «a que los internautas sólo accedan a aquellos contenidos que reafirman sus propias posiciones o gustos e ignoren las de quienes no piensan como ellos. En parte por el propio funcionamiento del algoritmo de Google, que nos jerarquiza la información en función de nuestras preferencias habituales. Pero también por nuestra tendencia a agregarnos comunicativamente con quienes tenemos afinidad. Al final, Internet nos ofrecería un espejo de lo que ya somos o pensamos y acabaría por introducirnos en distintos guetos comunicativos, alejándonos del ideal democrático de la sana confrontación de opiniones». VAllespín OÑA, F. (2011): op. cit., pp. 57-60. 
los antiguos atenienses votaban físicamente, los ciudadanos actuales voten virtualmente ${ }^{79}$.

La duda surge al plantearse si realmente la transformación es tan sencilla y carente de riesgos. Es posible presentar diversidad de críticas. Por citar algunas: la, en muchos casos, alarmante falta de una regulación que desarrolle y explique apropiadamente el ejercicio conjunto de participación y TIC y la inseguridad jurídica resultante ${ }^{80}$; la dificultad que para cualquier acto de control sobre el proceso electoral supone el hecho de que la transformación de los votos individuales en un resultado colectivo se realice mediante instrumentos informáticos que no necesariamente han de conocer otros sujetos más que sus programadores $^{81}$; la problemática que supone introducir actores privados (las empresas que crean las plataformas de voto electrónico o el programa informático que permite la votación), cuyo único objetivo es el beneficio económico, en un proceso público como es el voto (siendo que además habitualmente dichos sujetos privados son remunerados por el Gobierno de turno, el cual puede ser sujeto interesado en el resultado electoral); el riesgo de que no se respete el secreto en el voto al tener que identificarse para poder votar (introducir los datos personales en la máquina de votación) o que no se respete la libertad de voto al votar desde entornos no seguros ${ }^{82}$; así como el mantenimiento de todas los críticas alegados frente a la democracia participativa (simplificación de la política, riesgo de populismo, etc.) con el único cambio del instrumento (del físico al virtual) utilizado en la manifestación de la voluntad popular.

79 «Son interminables las ventajas que implica la implantación de la democracia, la participación y el gobierno electrónicos: eficacia, eficiencia, transparencia, comodidad, participación y cultura participativa, inclusión, estructuración de la participación política de los ciudadanos y los grupos en los que se integra, facilitación de la memoria política, pluralismo, entre otros». CoTINO Hueso, L. (2007): op. cit., pp. 84-85.

80 «Lo habitual —y muy negativo en la práctica— es que las normas se limiten a añadir como «cuña» que el derecho o instrumento participativo «se podrá ejercer por medios electrónicos». Y punto». Cotino Hueso, L. (2012): op. cit., p. 33.

81 «Las operaciones técnicas conducentes al escrutinio electrónico requieren también aquí de ciertos conocimientos específicos, normalmente informáticos, que no se encuentran al alcance ni de la mayoría de autoridades electorales ni de la mayoría de votantes u observadores (...) tendrán que aceptarse como hechos consumados los datos entregados por un procedimiento automático cuyo funcionamiento se desconoce y, por lo tanto, tampoco puede controlarse». BARRAT I Esteve, J. (2009): «Observación electoral y voto electrónico», Revista catalana de Dret públic, n. ${ }^{\circ} 39$, pp. 277-296.

82 Barrat i Esteve, J. (2012): «El secreto del voto en el sufragio por internet», Revista mexicana de análisis político y administración pública, Universidad de Guanajuato, vol. 1, n. ${ }^{\circ}$ 2, p. 58. 


\section{La necesidad del control}

Cuando un representante político toma una decisión en el ejercicio de sus funciones es posible identificarle y predicar de él una responsabilidad tanto política como, incluso, judicial. Es factible controlarle y cumplir el principio de que todo ejercicio de poder político requiere en democracia de su correspondiente control. Pero, ¿cómo es posible ejercer dicho control sobre los miles o millones de personas que participan en un instrumento participativo?

El ciudadano puede ejercer control sobre sus representantes a través del voto. Las instituciones representativas pueden controlarse entre ellas ${ }^{83}$. Pero el control sobre los miembros de un instrumento participativo resulta mucho más complejo, pues ni tienen ninguna responsabilidad pública sobre la cual pedir responsabilidades, ni son titulares de ningún cargo que controlar (más allá del hecho de ser ciudadanos) y ni siquiera es factible cuantitativamente tratar de pedir responsabilidades a millones de personas que, por ejemplo, participen en un referendo de ámbito nacional.

Del mismo modo que no se puede enjuiciar a los ciudadanos por elegir a un gobernante que después delinca (o sobre el que ya existan procedimientos judiciales abiertos) como si de cómplices del delito se tratara, tampoco se puede controlar a los que tomen una decisión disparatada u objetivamente dañina en un instrumento participativo. ¿Se les podría meter a todos en la cárcel? ¿Hacerles dimitir de su condición de ciudadanos? La mera idea de predicar la idea de control político sobre una muchedumbre introduce a aquel que lo plantea en el absurdo.

Es por ello que uno de las críticas básicas a la democracia participativa es que enajena poder político de unos sujetos a los que sí es posible controlar (los representantes) y lo entrega a otros sujetos a los que no es posible controlar (los ciudadanos), eliminando con ello una de las garantías esenciales del modelo democrático.

Es cierto que es posible idear mecanismos, si no de control político, sí al menos de fiscalización de que el instrumento participativo haya cumplido los objetivos para los cuales se ideó (tales como oficinas públicas que verifiquen que los fondos se gastaron en lo decidido por los ciudadanos, que las obras comprometidas se realizaron, etc. ${ }^{84}$ ), pero también es cierto que sean o no positivos los

${ }^{83}$ Como indica Molas citando a Stuart Mill: «la misión más propia de una asamblea representativa es la vigilancia y control del Gobierno». Molas, I. (2011): op. cit., p. 99.

${ }^{84}$ Así, en los presupuestos participativos de Rubí (Barcelona) se creó una comisión del Consejo de ciudad cuya función era elaborar un informe de evaluación de la aplicación de los acuerdos adoptados en los presupuestos participativos que se presentaba a las asambleas territoriales en la siguiente edición de los mismos. Para ampliar sobre el caso de Rubí vide VVAA (2001): Experiències de participació ciutadana en els municipis catalans, Barcelona, Escola d’ Administració Pública de 
resultados de la decisión popular, nadie puede a posteriori acudir a los ciudadanos a exigirles responsabilidades. Lo cual plantea la cuestión esencial: ¡es conveniente en democracia permitir que se ejerza el poder sin control?

\section{La atracción de lo representativo}

La democracia de los modernos, la democracia tal como se concibe desde las revoluciones liberales, es representativa. Tan pronto como las revoluciones liberales se materializan queda claro que el pueblo, en tanto que poder constituyente, pueden tener un poder absoluto mientras dura el acto constitucional por el que se forja el Estado, pero agotado éste, queda al margen de la acción política directa, siendo los poderes constituidos, las instituciones representativas, las llamadas a ejercer la acción política. Es por ello que, desde que surge la democracia contemporánea, la apelación a la intervención directa del pueblo en política más resulta algo ajeno que propio del modelo representativo, siendo que por su propia naturaleza y salvo contadas excepciones (tales como la elaboración de una Constitución) el ciudadano materializa su acción política en el voto periódico por el cual elige a sus representantes, pero no en actos de decisión política directa y $\sin$ intermediarios ${ }^{85}$.

Desde este punto de partida, cualquier fórmula de democracia participativa que se trate de insertar en el modelo representativo se constituye en gran medida en un ente ajeno al todo del que pasa a formar parte, sufriendo una tendencia hacia la pérdida de su condición estrictamente participativa en virtud de una deriva representativa. $\mathrm{O}$, por decirlo de otro modo, todo instrumento participativo tiene altas posibilidades de ser manipulado o, cuando menos (y por no dotar al acto de un carácter peyorativo), dirigido por los gobernantes y los representantes, verdaderos directores de la acción política, desvirtuando su carácter de gobierno directo de los ciudadanos y convirtiéndolo en una herramienta al servicio del poder o, como mínimo, no competitivo con éste ${ }^{86}$.

Catalunya y Blanco, I. «Presupuestos participativos en Rubí. Innovaciones, límites y retos de una experiencia pionera» en Ganuza Fernández, E. y Álvarez de Sotomayor, C. (2003): Democracia y presupuestos participativos, Barcelona, Icaria Editorial, pp. 155-173.

85 «El pueblo como titular del poder constituyente soberano del Estado era el único encargado de elaborar y aprobar la Constitución. Ahora bien como, por definición, el poder soberano es absoluto y total, y como quiera que de lo que se trataba era de limitar el poder, formó parte de la esencia del Estado Constitucional, ya en sus comienzos, la idea de que una vez aprobada la Constitución el poder constituyente debía desaparecer». VeGA, P. de (1998): op. cit., p. 28.

86 Basta con ver la regulación que en España realiza la LO 3/1984, de 26 de marzo, reguladora de la iniciativa legislativa popular, para comprobar como en la práctica el resultado del 
Esta atracción de lo representativo se materializa en muchas ocasiones en la propia regulación de los instrumentos participativos, los cuales habitualmente han de ser puestos en marcha por los poderes públicos, no por los ciudadanos, y mayoritariamente no tienen efectos vinculantes, sino que la ejecución de su resultado dependerá de la voluntad del responsable político. Se percibe así el carácter eminentemente complementario de la democracia participativa respecto de la representativa y como muchas veces no acaba siendo otra cosa que un instrumento en manos de los gobernantes para tratar de legitimarse ante los ciudadanos ${ }^{87}$.

También es destacable la propia dinámica de la práctica de la democracia participativa que, en casos como el suizo, donde la tasa de participación ha bajado desde el 60\% al 40\% desde el final de la Segunda Guerra Mundial hasta el presente, parece indicar que el recurso frecuente a los instrumentos participativos acaba agotando a los ciudadanos, los cuales abandonan progresivamente el ejercicio de su derecho a la participación y se limitan a participar en las elecciones representativas y en muy contadas experiencias participativas ${ }^{88}$.

\section{CONCLUSIONES}

En el presente se viven momentos en los que se tiene la conciencia de que se cambia de uno a otro periodo histórico pero en los que existen muchas más dudas que certezas sobre aquel al que se dirige la democracia y en el que las pocas sombras que sobre el futuro se alcanzan a vislumbrar nada sino temores y amenazas parecen dibujar sobre el horizonte. Como indica de Vega:

«Ante la escandalosa y progresiva reducción de los espacios políticos estatales, en los que tradicionalmente se venían ejercitando el vivere libero y el vivere civile de los

proceso participativo será el que las Cortes y no los ciudadanos decidan, hasta el punto de que la proposición de ley elevada por los ciudadano mediante la iniciativa popular podrá ser libremente modificada por los representantes públicos aunque esto suponga desvirtuarla.

87 Este pesimismo sobre la democracia participativa y su tendencia a perder su esencia al difuminarse en el todo político dominante recuerda al argumento dado por Michels sobre la tendencia de la democracia a convertirse en oligarquía: «Cuando las democracias han alcanzado cierto estadio de desarrollo, sufren una transformación gradual, adoptan el espíritu aristocrático y en muchos casos las formas aristocráticas contra las cuales en un principio tan fervorosamente combatieron (...) después de una era de gloriosas batallas y de ignominioso poder, terminan fusionándose con la antigua clase dominante». Michels, R. (1962): Political parties: A sociological study of the oligarchical tendencies of modern parties, Nueva York, Collier books, p. 354, en DAHL, R. A. (1992): op. cit., p. 325.

88 Vide FonT, N. (1998): Democràcia i participació ciutadana, Barcelona, Mediterrània. 
ciudadanos, nada tiene de sorprendente que se plantee el problema de cómo redefinir los ámbitos de la democracia en el proceso inexorable de la mundialización.» ${ }^{89}$

Que la democracia participativa aparezca, por tanto, como una potente opción para intentar mejorar o, incluso, salvar la democracia no es extraño. La cuestión es si es el remedio adecuado. Si puede ayudar en algo. Si tiene capacidad para contribuir a la mejora de la democracia. O, si evaluando los riesgos que implica y los beneficios que puede traer, merece la pena apostar por ella. En este punto se produce la oposición entre entusiastas y escépticos de la participación. La democracia participativa actúa como una cuña de participación directa que se introduce en el entramado representativo (formado por partidos políticos, sindicatos, grupos de interés, etc.) alterando sus equilibrios de poder y generando nuevos espacios para el ciudadano. Este hecho aparece como un gran progreso para sus entusiastas y como un gran peligro para sus escépticos. Siendo el mismo hecho, las lecturas son radicalmente distintas. Pues si se considera que los partidos políticos y los políticos profesionales son el mal de la democracia representativa (o, al menos, uno de ellos), una mayor participación directa será positiva al limitar y controlar el poder de dichos políticos, pero si se concluye que al ejecutar esa mayor participación se corre el riesgo de debilitar las instituciones representativas, simplificar la toma de decisiones políticas, rebajar los controles democráticos e, incluso, dar pie a derivas caudillistas en las que el líder extraiga su poder de la apelación constante al pueblo, evidentemente no se puede más que denunciar que el riesgo no compensa el beneficio.

Sin embargo, la democracia es movimiento y necesita del movimiento para sobrevivir ${ }^{90}$ y si una mayor apertura a la participación de los ciudadanos en la vida pública parece elemento en línea con sus transformaciones anteriores (exten-

89 VEGA, P. de (2003): «La democracia como proceso: consideraciones en torno al republicanismo de Maquiavelo», Revista de estudios políticos, n. ${ }^{\circ}$ 120, pp. 37-39.

90 Pues quizá el peor enemigo de la democracia sea la autocomplacencia que lleva a creer que ya no debe cambiar, ni evolucionar más. En palabras de Jáuregui Bereciartu: «(...) la ausencia de enemigos externos. Tal ausencia ha asentado a la democracia en la comodidad. Se ha extendido una creencia generalizada que tiende a considerar los vigentes modelos democráticos como los mejores sistemas «posibles», cuando en realidad tan sólo constituyen los mejores sistemas «hasta ahora conocidos». Esto ha traído como consecuencia una renuncia en toda regla, por parte de los actuales sistemas políticos, a la búsqueda permanente de la «utopía» democrática, del ideal democrático. Se ha olvidado que la democracia es el producto resultante de la tensión dialéctica existente entre sus hechos y sus valores, y que una democracia sin valores es una democracia a la deriva, una democracia inerme, incapaz de generar los anticuerpos necesarios para responder a las amenazas y desafíos que se le plantean, e incapaz de regenerarse y adaptarse a las nuevas situaciones. De esta forma, las actuales democracias inermes corren el riesgo de convertirse en democracias definitivamente inertes». Jauregui Bereciartu, G. (1998): op. cit., pp. 102-103. 
sión del sufragio a los no propietarios, a las mujeres, a las minorías raciales...), no parece sensato que tal progreso suponga, por su errado desarrollo y puesta en marcha, por un ansia en reformarlo todo por considerarlo todo degenerado, una regresión democrática en la que se pongan en duda no ya el parlamentarismo y la naturaleza esencialmente representativa de la democracia moderna, sino incluso el respeto a las minorías o los controles que todo ejercicio de poder necesita. ${ }^{91}$ La aparición de líderes carismáticos que, en nombre del pueblo y de la voluntad manifestada por éste en instrumentos participativos, proceden a identificar dicho pueblo con ellos y dicha voluntad con la suya no es, desde luego, nada novedoso. La historia moderna de las fórmulas de participación directa y el rechazo que las mismas generan en no pocos ámbitos es hijo de la utilización torticera que repetidamente se les ha dado desde el poder.

En cualquier caso, la democracia participativa no deja de ser un conjunto de instrumentos jurídicos que en sí son tan peligrosos o beneficiosos como peligroso o beneficioso se considere que es consultar a los ciudadanos. Pueden ser utilizados para ratificar una Constitución sirviendo de refuerzo a las instituciones representativas y al texto aprobado por ellas, pero también pueden ser utilizados para derogar sistemáticamente leyes aprobadas por el parlamento. Pueden fortalecer el parlamentarismo o pueden debilitarlo. Que finalmente sus efectos sean positivos o negativos dependerá en gran medida no tanto del instrumento en sí, sino del operador que lo ponga en funcionamiento y de sus intenciones. Posiblemente, no serán las mismas las que albergue un caudillo deseoso de consolidar su poder evadiéndose del control parlamentario y judicial, que las propias de un grupo de vecinos de un pequeño municipio que trate de evitar que su alcalde les imponga un determinado diseño para una plaza local.

Tampoco es posible hacer tabla rasa y considerar a todos los instrumentos de la democracia participativa como idénticos en sus posibles efectos ya sean estos positivos o negativos. La mayoría de las críticas planteadas son fácilmente atribuibles a aquellos instrumentos participativos que consisten en una pregunta directa (sea un referendo, una revocatoria de mandato, etc.) que no permite al ciudadano más que optar entre dos opciones antagónicas, anulando toda posible transversalidad o pacto, potenciando el personalismo en la política y, en definitiva, cayendo en los defectos señalados. No parece que las mismas críticas, o al menos no todas ellas, puedan ser tan fácilmente predicadas de unos presupuestos

91 Ya decía Dahl que no todo cambio es necesariamente bueno. Se puede evolucionar o se puede involucionar: «A pesar de la opinión, de corte romántico, de que la evolución representa siempre un rejuvenecimiento saludable, lo cierto es que, moral y políticamente, el cambio es decididamente neutro». DAHL, R. A. (2009): op. cit., p. 165. 
participativos o de un jurado ciudadano en donde no existe tal pregunta directa dotada de respuestas antagónicas y donde el proceso, si consigue algo, es precisamente tanto la negociación, como la ampliación del consenso a la hora de tomar una decisión pública, como, en principio, la huida de todo personalismo. Por ello, las críticas a la democracia participativa expuestas en este artículo hay que entenderlas al todo, pero asumiendo que dentro de ese todo hay que valorar las peculiaridades de cada instrumento participativo.

No obstante, es evidente que la democracia participativa parte de una idea fuerza: dotar de más poder a los ciudadanos. Y esta idea supone tanto alterar el equilibrio de poder de las instituciones representativas, como introducir elementos que pueden entrar en conflicto con la dinámica de la representación (como por ejemplo la dificultad de controlar y predicar responsabilidad de los ciudadanos que toman una decisión política en un instrumento participativo). Si las posibilidades de que esta alteración lleve a debilitar el entramado institucional y con él la democracia misma no son menores sin que medie intervención malintencionada alguna de un determinado partido o líder populista (o grupo económico o de poder interesado en conseguir un determinado objetivo políticoeconómico), mediando esta intervención y existiendo esta voluntad concreta el riesgo que se corre puede resultar inaceptable.

Tal vez los beneficios que pueda aportar la democracia participativa no compensen los riesgos que supone. Tal vez la reforma que la democracia necesita ha de proceder de su propia realidad representativa y de la reforma y mejora de las distintas instituciones de las que se compone, sin olvidar la necesaria cuota de participación directa de los ciudadanos, aumentándola en áreas concretas (que los ciudadanos puedan iniciar los procesos, que los resultados de los mismos sean vinculantes...), pero sin caer en la respuesta sencilla, rápida y fácil que dice que si los políticos son el problema la gente es la solución, evitando la búsqueda del ideal en la reforma democrática, por ser posiblemente la democracia un sistema de gobierno que, como los hombres de los que se compone, mucho más se acerca a la imperfecta frustración de la realidad, que a ningún perfecto ideal. En palabras de Dahl:

«Las imperfecciones de cualquier democracia actual son tan obvias y enormes que la discrepancia palpable entre el ideal y la realidad estimula de continuo desenfrenadas esperanzas de tornar de algún modo real lo ideal; pero las soluciones materializables se muestran esquivas y quienes con tanta facilidad construyen en su imaginación una democracia ideal descubren muy pronto que es muchísimo más difícil, o imposible, construir ese ideal en el mundo real.» ${ }^{92}$

92 DAHL, R. A. (1992): op. cit., pp. 374-375. 
Mayor participación no equivale a mejor democracia. Una mayor participación sin una mejor representación puede desequilibrar los equilibrios de poder de la democracia, no mejorarla. La democracia participativa puede mejorar la democracia, pero utilizada para intereses y fines particulares puede llevar a justo lo contrario: el debilitamiento de las instituciones representativas y el excesivo fortalecimiento de un Ejecutivo libre de otro control que no sea el (supuestamente) ejercido por las masas constantemente movilizadas precisamente por dicho Ejecutivo.

No es la situación actual la primera vez en que el parlamentarismo y la democracia representativa han sido duramente criticadas, tampoco es la primera en que las apelaciones al pueblo han acabado convirtiéndose en aclamaciones al líder. Más participación, desde luego, pero en primer lugar y por delante de todo, mejor representación.

\section{BIBLIOGRAFÍA}

Aragón Reyes, M. (2000): «Democracia y representación. Dimensiones objetiva y subjetiva del derecho de sufragio», Corts: Anuario de Derecho parlamentario, n. ${ }^{\circ}$ 9, pp. 37-60.

Asensi Sabater, J. (2012): «Crisis teórica, transiciones constitucionales», Revista Derecho del Estado, n. ${ }^{\circ}$ 28, pp. 9-35.

- (2002): «La reanimación del parlamento: exigencia de un «constitucionalismo consecuente»», Corts: Anuario de Derecho parlamentario, n. ${ }^{\circ} 12$, pp. $29-52$.

Attlee, C. (I954): As it happened, Londres, Heinemann.

Balaguer Callejón, F. (2013): «Una interpretación constitucional de la crisis económica», Revista de Derecho Constitucional Europeo, n. ${ }^{\circ} 19$, pp. 449-454.

BArrat i Esteve, J. (2012): «El secreto del voto en el sufragio por internet», Revista mexicana de análisis político y administración pública, Universidad de Guanajuato, vol. 1, n. $^{\circ}$, pp. 57-72.

- (2009): «Observación electoral y voto electrónico», Revista catalana de Dret públic, n. ${ }^{\circ}$ 39, pp. 277-296.

Bejarano, A. M. y Segura, R. (2013): «Asambleas constituyentes y democracia: una lectura crítica del nuevo constitucionalismo en la región andina», Colombia Internacional, n. ${ }^{\circ}$ 79, pp. 19-48.

Blanco, I. «Presupuestos participativos en Rubí. Innovaciones, límites y retos de una experiencia pionera» en Ganuza Fernández, E. y Álvarez DE SoTOMAYOR, C. (2003): Democracia y presupuestos participativos, Barcelona, Icaria Editorial, pp. 155-173. 
Bobbio, L. (2006): «Democrazia partecipativa- Dilemmi della democrazia partecipativa», Democrazia e diritto, n. ${ }^{\circ} 4$, pp. 11-26.

Cotino Hueso, L. (2012): «La regulación de la participación y de la transparencia a través de internet y medios electrónicos. Propuestas concretas», P3T Journal of public policies and territories, n. ${ }^{\circ}$ 2, vol. 1, pp. 27-39.

- (2007): «Retos jurídicos y carencias normativas de la democracia y la participación electrónicas», Revista catalana de Dret públic, n. 35, pp. 75-120.

Dahl, R. A. (2009): La poliarquía. Participación y oposición, Madrid, Tecnos.

- (1992): La democracia y sus críticos, Barcelona, Paidos.

Fernández-Miranda Campoamor, C. y Fernández-Miranda Campoamor, A. (2003): Sistema electoral, partidos politicos y parlamento, Madrid, Colex.

Floridia, A. (2007): «La democrazia deliberativa, dalla teoria alle procedure. Il caso della legge regionale toscana sulla partecipazione», Istituzioni del federalismo: rivista di studi giuridici e politici, n. ${ }^{\circ}$ 5, pp. 603-681.

Font, N. (1998): Democràcia i participació ciutadana, Barcelona, Mediterrània.

Gargarella, R. (2013): «Dramas, conflictos y promesas del nuevo constitucionalismo latinoamericano», Anacronismo e irrupción. Revista de Teoría y Filosofía Política Clásica y Moderna, vol. 3, n. ${ }^{\circ}$ 4, pp. 245-257.

- (1995): «Crisis de representación y constituciones contramayoritarias», Isonomía: Revista de teoría y filosofía del Derecho, n. ${ }^{\circ}$ 2, pp. 89-108.

- (1994): «Crisis de representación, deliberación y «political correctness»», Anuario de filosofía del Derecho, n. ${ }^{\circ} 11$, pp. 243-250.

HäBERle, P. (2006): «Siete tesis para una teoría constitucional del mercado», Revista de Derecho Constitucional Europeo, n. ${ }^{\circ}$, pp. 11-30.

Habermas, J. (2005): «Tres modelos de democracia: sobre el concepto de una política deliberativa», Polis: Revista Latinoamericana, n. ${ }^{\circ} 10$.

- (1998): Facticidad y validez. Sobre el derecho y el Estado democrático de derecho en términos de teoría del discurso, Madrid, Trotta.

Held, D. (1992): Modelos de democracia, Madrid, Alianza.

Herrero lera, M. en Alzaga Villaamil, Ó. (1985): Comentarios a las Leyes Políticas. Constitución Española de 1978, tomo VII, Madrid, Revista de Derecho Privado, Editoriales de Derecho Reunidas.

Jauregui Bereciartu, G. (2014): «Democracia y sociedad tecnológica», Revista vasca de administración pública, n. ${ }^{\circ}$ 99-100, pp. 1737-1752.

- (1998): «Democracia: ¿declive temporal u ocaso definitivo?», Revista internacional de filosofía política, n. ${ }^{\circ} 11$, pp. 102-126.

Kelsen, H. (1979): Teoría general del Derecho y del Estado, Méjico D. F., Dirección general de publicaciones de la Universidad Nacional Autónoma de Méjico.

- (1977): Esencia y valor de la democracia, Madrid, Guadarrama, Colección Punto Omega. 
Lissidini, A. (1998): «Una mirada crítica a la democracia directa: El origen y las prácticas de los plebiscitos en Uruguay», Perfiles latinoamericanos: Revista de la Facultad Latinoamericana de Ciencias Sociales, Sede México, n. ${ }^{\circ} 12$, pp. 169-200.

LuCAs Verdú, P. (1981): «Constitución española de 1978 y sociedad democrática avanzada», Revista de Derecho Político, n. ${ }^{\circ} 10$, pp. 7-46.

Molas, I. (2011): Derecho constitucional, Madrid, Tecnos.

Montero, D. (2009): La casta: el increíble chollo de ser político en España, Madrid, La esfera de los libros.

Presno Linera, M. A. (2014): «Partidos políticos y movimientos ciudadanos en la sociedad del riesgo y la desconfianza», La metamorfosis del Estado y del Derecho, Fundamentos: Cuadernos monográficos de teoría del estado, derecho público e bistoria constitucional, n. ${ }^{\circ}$, Universidad de Oviedo, pp. 213-252.

- (2012): «La participación ciudadana en el procedimiento legislativo como parte de la esencia y valor de la democracia», Asamblea: revista parlamentaria de la Asamblea de Madrid, n. ${ }^{\circ} 27$, pp. 85-120.

Qvortrup, M. «La experiencia estadounidense de 1776 a 2012» en WELP, Y. y Serdült, U. (2014): La dosis hace el veneno. Análisis de la revocatoria de mandato en América Latina, Estados Unidos y Suiza, Quito, Instituto de la Democracia.

RAmíreZ NÁrdiz, A. (2014): «La participación como respuesta a la crisis de la representación: el rol de la democracia participativa», Revista de Derecho Político, n. ${ }^{\circ}$ 90, pp. 177-210.

- (2012): Guía práctica de la democracia participativa. Conocer la democracia participativa y aprender a usarla, Madrid, Dykinson.

- (2009): «El debate en torno a los mecanismos de democracia participativa durante el proceso constituyente español», Cuadernos constitucionales de la Cátedra Fadrique Furió Ceriol, n. ${ }^{\circ}$ 67-68, pp. 167-178.

Rubio NúÑez, R. (2007): «La guerra de las democracias», Asamblea: revista parlamentaria de la Asamblea de Madrid, n. ${ }^{\circ}$ 16, pp. 79-107.

- (2006): «Venezuela. La pesadilla revolucionaria y el camino hacia el totalitarismo», La Ilustración liberal: revista española y americana, n. ${ }^{\circ}$ 29, pp. 89-100.

SARtori, G. (2007): ¿Qué es la democracia?, México, D. F., Taurus.

Schumpeter, J. A. (1971): Capitalismo, socialismo y democracia, Madrid, Aguilar.

Subirats i Humet, J. (2011): “¿Qué democracia tenemos? ¿Qué democracia queremos?», Historia actual online, n. ${ }^{\circ}$ 26, pp. 115-132.

VALlespín OÑA, F. (2011): «Redes sociales y democracia: ¿un cambio cualitativo?», Telos: Cuadernos de comunicación e innovación, n. . 89, pp. 57-60.

- (1996): «Sociedad civil y «crisis de la política»", Isegoría: Revista de filosofía moral y política, n. 13 , pp. 39-58.

VEGA, P. de (2003): «La democracia como proceso: consideraciones en torno al republicanismo de Maquiavelo», Revista de estudios políticos, n. ${ }^{\circ}$ 120, pp. 7-44. 
- (1998): «Mundialización y Derecho Constitucional: la crisis del principio democrático en el constitucionalismo actual», Revista de estudios políticos, n. ${ }^{\circ} 100$, pp. 13-56.

VVAA (2001): Experiències de participació ciutadana en els municipis catalans, Barcelona, Escola d’ Administració Pública de Catalunya.

\section{JURISPRUDENCIA}

STC 103/2008, de 11 de septiembre, FJ. 2.

\section{PÁGINAS WEB}

PODEMOS, podemos.info, consultado febrero 2015.

Title:

MORE PARTICIPATION EQUAL THAN BETTER DEMOCRACY? ON CRITIC TO PARTICIPATORY DEMOCRACY

\section{Summary:}

I. Introduction. II. Representation Crisis and participatory democracy. III. Participatory democracy critics. 1. The populism accusation. 2. The simplification of politics. 3. The material impossibility and the internet role. 4. The control necessity. 5. The representative attraction. IV. Conclusions. V. Bibliography. VI. Jurisprudence. VII. Web pages.

\section{Resumen:}

En el presente, y en países como España, la crítica a la democracia representativa tal y como ésta se concibe actualmente parece ir más allá de la recurrente reflexión sobre la crisis de la representación para alcanzar niveles de enmienda a la totalidad en los que se aboga no ya por reformar aspectos concretos del modelo representativo, sino por replantear el modelo en su conjunto. No se propone un modelo político distinto que el democrático, pero sí se plantea una democracia distinta que, especialmente, y junto con la reforma de las instituciones 
y elementos representativos más característicos (siendo los partidos políticos el eje de estas reformas), busque una mayor participación de los ciudadanos en la vida pública en general y en la toma de decisiones políticas en particular encontrando en la democracia participativa uno de los pilares del nuevo modelo democrático propuesto. La cuestión surge al plantear si esta mayor participación de los ciudadanos es compatible con el modelo representativo y puede contribuir a cambiarlo mejorándolo o si, por el contrario, una mayor participación política de los ciudadanos puede conllevar efectos perniciosos, ya sean estos involuntarios y causados por limitaciones materiales de los instrumentos participativos, ya sean estos voluntariamente buscados por gobernantes y operadores políticos que, en nombre de una mejora democrática materializada mediante una mayor participación, no busquen otra cosa que alcanzar, mantener y aumentar su poder aun y a costa de un debilitamiento democrático materializado en un empeoramiento de la calidad de las instituciones representativas del Estado. Resulta, por tanto, relevante plantear si una mayor democracia participativa lleva necesariamente a una mejor democracia, o si sucede lo contrario. En este artículo, partiendo del rol de la democracia participativa como posible complemento que ayude a la mejora de la democracia representativa, se plantean las críticas a la democracia participativa y se trata de aportar una propuesta de respuesta a la pregunta de si una mayor participación es compatible con una mejor democracia, proponiéndose que no necesariamente y que dicha compatibilidad dependerá en gran medida no tanto de los instrumentos participativos en sí, sino de los sujetos políticos que los activen y de la voluntad e intenciones políticas que los mismos tengan.

\begin{abstract}
:
Nowadays, and in countries as Spain, the critic to the representative democracy as it is conceived in the present seems to go beyond the usual thought about the representation crisis to reach amendment to the whole levels where it is not any more asked to reform specific aspects of the representative model, but to rethink the whole model. It is not proposed a different political model than democratic one, but it is proposed a different democracy that, specially and together with the reform of the more characteristic representative institutions and elements (being the political parties the axis of these reforms), looks for a bigger participation of the citizens in public life in general and in the political decision making in particular finding in participatory democracy one of the pillars of the new proposed democratic model. The question arises when posing if this bigger citizens' participation
\end{abstract}


is compatible with the representative model and can contribute to change it improving it or if, conversely, a bigger citizens' political participation can lead to pernicious effects, both involuntary and caused by material limitations of participatory tools, both voluntary wished by rulers and political operators than, in the name of a political improvement materialized through a bigger participation, don't look for another thing but to reach, to keep and to increase their power even at the cost of a democratic weakening materialized in a worsening of the quality of the representative institutions of the State. It is, therefore, relevant to pose if a bigger participatory democracy necessarily leads to a better democracy, or if contrary happens. On this paper, starting from the role of participatory democracy as possible complement that helps to the improving of representative democracy, the critics to the participatory democracy are exposed and it is tried to give a proposal of answer to the question if a bigger participation is compatible with a better democracy, proposing that no necessarily and this compatibility will depend in a great way not so much on the tools themselves, but on the political subjects that activate them and on the will and political intentions that they have.

Palabras clave:

Democracia participativa, representación, crisis, crítica, populismo.

Key words:

Participatory democracy, representation, crisis, critic, populism. 